\title{
Risk and protective factors for meningococcal disease in adolescents: matched cohort study
}

Joanna Tully, Russell M Viner, Pietro G Coen, James M Stuart, Maria Zambon, Catherine Peckham, Clare Booth, Nigel Klein, Ed Kaczmarski, Robert Booy

\begin{abstract}
Objective To examine biological and social risk factors for meningococcal disease in adolescents.

Design Prospective, population based, matched cohort study with controls matched for age and sex in 1:1 matching. Controls were sought from the general practitioner. Setting Six contiguous regions of England, which represent some $65 \%$ of the country's population.

Participants 15-19 year olds with meningococcal disease recruited at hospital admission in six regions (representing 65\% of the population of England) from January 1999 to June 2000, and their matched controls.

Methods Blood samples and pernasal and throat swabs were taken from case patients at admission to hospital and from cases and matched controls at interview. Data on potential risk factors were gathered by confidential interview. Data were analysed by using univariate and multivariate conditional logistic regression.

Results 144 case control pairs were recruited (74 male (51\%); median age 17.6$)$. 114 cases (79\%) were confirmed microbiologically. Significant independent risk factors for meningococcal disease were history of preceding illness (matched odds ratio $2.9,95 \%$ confidence interval 1.4 to 5.9 ), intimate kissing with multiple partners (3.7, 1.7 to 8.1$)$, being a university student $(3.4,1.2$ to 10$)$ and preterm birth (3.7, 1.0 to 13.5). Religious observance $(0.09,0.02$ to 0.6$)$ and meningococcal vaccination $(0.12,0.04$ to 0.4$)$ were associated with protection.

Conclusions Activities and events increasing risk for meningococcal disease in adolescence are different from in childhood. Students are at higher risk. Altering personal behaviours could moderate the risk. However, the development of further effective meningococcal vaccines remains a key public health priority.
\end{abstract}

\section{Introduction}

Invasive meningococcal disease is a life threatening condition, with endemic and epidemic manifestations in developed and developing countries. ${ }^{12}$ A primary incidence peak occurs in children aged $<5$ years and a smaller peak in teenagers. ${ }^{1}$ The incidence of meningococcal disease in England ${ }^{2}$ and the United States $^{3}$ rose during the 1990 s, with a marked shift in age distribution towards older teenagers ${ }^{4}$ and a rise in disease due to serogroup C strains. ${ }^{5}$ This rise, together with a higher case fatality rate in the $15-19$ year age group, ${ }^{3}{ }^{4}$ caused much concern and was a major stimulus in the United Kingdom for developing the conjugate meningococcal serogroup $\mathrm{C}$ vaccine, which has been highly successful. $^{6}$

The reasons for the peak in meningococcal disease in teenagers are poorly understood. Greater transmission of meningococci has been implicated, ${ }^{7}$ as prevalence of carriage increases through childhood. ${ }^{8}$

Studies in the peak teenage years are limited to subgroups such as college students, ${ }^{910}$ or to small numbers enrolled in larger studies. ${ }^{112}$ Possible risk factors in children include deficiency of mannose-binding lectin ${ }^{13}$ preceding respiratory infections, particularly influenza $\mathrm{A},{ }^{14-16}$ overcrowding, ${ }^{11}{ }^{17}$ poverty, ${ }^{11}$ passive smoke exposure, ${ }^{11}{ }^{12}$ and mouth kissing. ${ }^{.1}$

Adolescence is a period of biopsychosocial maturation during which the adoption of potentially risky behaviours may produce a distinct risk profile. Studies have found living in college dormitories, ${ }^{9}{ }^{10}$ patronage of campus bars, and active smoking $^{18}$ to be risk factors. Other factors relevant to teenagers may include infection with Epstein-Barr virus, ${ }^{19}{ }^{20}$ behaviours such as deep kissing, and substance misuse..$^{21}{ }^{22}$ Religious observance may be protective. ${ }^{23}$ We conducted a matched cohort study of meningococcal disease in adolescence to examine potential risk and protective factors.

\section{Methods}

\section{Study setting and subjects}

We conducted a prospective, population based, matched, cohort study covering six contiguous regions of England (North Thames, South Thames, Anglia and Oxford, South West, Trent, West Midlands), which represent about $65 \%$ of the country's population. The process of gaining ethical approval was challenging due to the wide geographic area and nature of both the study content and subject age group. It had implications on the recruitment of subjects and became the subject of a paper. ${ }^{24}$ The research fellow and research nurse collected data from 5 January 1999 until 9 June 2000, covering two winter peaks of meningococcal disease. Eligible subjects were teenagers aged 15-19 who had been admitted to hospital with a primary clinical diagnosis of meningococcal infection (signs of septicaemia or meningitis in association with hemorrhagic rash, or both). Laboratory confirmation of disease was sought at the reference laboratory in Manchester through culture or detection by polymerase chain reaction of Neisseria meningitidis from a normally sterile site or serodiagnosis in a patient with a clinically compatible illness.

Consultants in communicable disease control, clinicians, the national meningococcal reference unit, or the Meningitis 
Research Foundation helpline notified eligible subjects of the study centre by telephone or electronic mail. After referral of a possible case, the research fellow contacted the attending clinician to confirm the clinical diagnosis and to obtain informed consent for the patient's participation. We excluded cases if identified after the fifth day of admission to hospital, the subject had died, the attending doctor declined to participate, the subject did not speak English, or approval from the local research ethics committee had not yet been obtained.

We recruited controls from the case patient's general practitioner's list of patients. Each general practitioner was asked to contact the three patients on their list of the same sex as, and closest date of birth to, the case. This was to control selection bias by the doctor. We preferentially recruited the control nearest in age to the case. If none of these subjects consented we asked the doctor to send invitation letters to the next three who were nearest in age. Trained researchers interviewed subjects confidentially at home shortly after discharge from hospital. Each case-control pair was interviewed on the same day where possible. The interviewer completed standardised questionnaires.

As we were interested in specific, not necessarily habitual, behaviours, we obtained data from cases pertaining to the two week period before admission to hospital. We reduced the time between illness and interview and used memory aides (timelines, calendars, and personal diaries) to reduce recall bias for cases. To reduce recall bias in controls, we questioned subjects about the two week period immediately preceding interview. Because of this difference in time periods, it was not possible to blind researchers to the status of cases and controls.

\section{Data collection}

We obtained data from the participants on preceding illness: symptoms of prodromal illness (in cases) and preceding illness (in cases and controls-for example, fever, headache, cough, rhinorrhoea, sore throat); on health behaviours: passive smoke exposure (number of smokers in participant's place of residence), active smoking (one or more cigarettes per day), and consumption of alcohol and illicit drugs; on intimacy behaviours: superficial and deep kissing contacts, close social contacts, and sharing of beds and bedrooms; on social behaviours: attendance at religious ceremonies, leisure activities, and social activities; on socioeconomic variables: education or employment status, living conditions. Data obtained from the participant's head of household included birth history (preterm delivery defined as gestation $<37$ weeks); meningococcal vaccination history; and details of occupation, crowding, and home and car ownership. We regarded participants as head of household if they were employed or living independently.

Case patients gave a blood sample, pernasal swab, and throat swab within five days of admission. At interview, we collected a convalescent blood sample from cases and a blood sample, throat swab, and pernasal swab from controls. We considered the control blood sample comparable to the case convalescent sample as it was taken at a similar time (median difference of 0 days; interquartile range of -28 days to 0 days). We placed swabs in viral transport medium and transported them immediately to the Health Protection Agency (HPA; formerly Public Health Laboratory Service, PHLS), together with the blood sample. Blood samples were separated with serum divided into 4 aliquots and stored at $-20^{\circ} \mathrm{C}$. The viral transport medium containing the swabs was stored at $-70^{\circ} \mathrm{C}$.

The Health Protection Agency's national meningococcal reference unit in Manchester performed meningococcal serogroup $\mathrm{B}$ and $\mathrm{C}$ serology. ${ }^{25}$ Laboratory technicians at the University of
Edinburgh used indirect immunofluorescence to perform virology for Epstein-Barr virus. Immunoglobulin G antiviral capsid antibody positivity was taken to indicate past infection with Epstein-Barr virus. Recent infection with Epstein-Barr virus was defined as positivity for IgM antiviral capsid antibody. ${ }^{26}$ The respiratory virus unit at the Central Public Health Laboratory in north London performed influenza serology and reverse transcriptase polymerase chain reaction analysis were performed. ${ }^{27}$ Haemagglutinin inhibition antibody titres were performed for influenza A subtypes H3N2 and H1N1 and for influenza B. Titres of $>320$ against influenza A H3N2 and $>80$ for influenza $\mathrm{B}$ were taken to indicate infection within the last year (personal communication, Maria Zambon, Health Protection Agency, 2000).

Laboratory technicians extracted DNA and RNA from throat and pernasal swabs. The Health Protection Agency undertook analysis by reverse transcriptase polymerase chain reaction for influenza A and B and respiratory syncytial virus and by polymerase chain reaction for Chlamydia pneumoniae and Mycoplasma pneumoniae. ${ }^{28}$ A lab technician determined mannosebinding lectin haplotypes at the Institute of Child Health in London. The exon 1 region of the mannose-binding lectin structural gene and promoter region polymorphisms were determined by using previously described heteroduplex procedures and the results used to predict concentrations of mannose-binding lectin. Subjects were divided into groups of low, medium, or high production of mannose-binding lectin, with low producers defined as either those subjects who were homozygous, or compound heterozygous for exon 1 mutations or those heterozygous for an exon 1 mutation and also carrying the low promoter variant. ${ }^{29} 30$

\section{Statistical analysis}

We used Stata 6 (College Station, Texas, YEAR?? OUTSTANDING QUERY) for our statistical analyses. We used Mantel Haenzel odds ratios to perform univariate analysis. We performed multivariate stepwise logistic regression; we included variables if they had a univariate significance level of $\mathrm{P}<0.2{ }^{31}$ We determined socioeconomic status by household ownership of car and home and by subject occupation and included this a priori in the model. As risk behaviours may vary by time of year, we also included a seasonality variable in the model, with meningococcal disease high season defined as 70 or more cases per week. We made power calculations: in respect to active smoking, we speculated that the prevalence in cases and controls would be $30 \%$ and $12 \%$, respectively, requiring 116 case-control pairs to provide $95 \%$ confidence intervals with $90 \%$ power. Using a similar approach for kissing, we hypothesised that multiple exposures in the previous fortnight might be found in $40 \%$ of cases and $20 \%$ of controls, requiring 118 pairs. These calculations did not take account of matching.

\section{Results}

During the study period, public health units in the study regions received 319 statutory notifications of meningococcal disease in teenagers aged $15-19$. Of these, 244 were referred to the study centre and 153 were recruited. Of the 91 cases referred but not recruited, 23/244 (9\%) were referred after the fifth day of admission, $18(7 \%)$ came from districts where local ethical approval was delayed, $16(7 \%)$ died before recruitment, $12(5 \%)$ had an alternative diagnosis, $11(5 \%)$ refused, in $5(2 \%)$ the clinician in charge refused, 3 (1\%) did not speak English, and 3 (1\%) were not recruited for miscellaneous reasons. Of the 153 recruited, two died after recruitment, two later refused to participate, and five 
Research

Table 1 Demographic data on participating cases and controls. Values are numbers (percentages)

\begin{tabular}{|c|c|c|}
\hline Category & Cases $(n=144)$ & Controls $(n=144)$ \\
\hline \multicolumn{3}{|l|}{ Age in years } \\
\hline 15 & $25(17)$ & $23(16)$ \\
\hline 16 & $28(19)$ & $23(16)$ \\
\hline 17 & $30(21)$ & $34(24)$ \\
\hline 18 & $28(19)$ & $27(19)$ \\
\hline 19 & $33(23)$ & $37(26)$ \\
\hline \multicolumn{3}{|l|}{ Ethnicity } \\
\hline White & $128(89)$ & $134(93)$ \\
\hline Black & $5(3)$ & $2(1)$ \\
\hline Indian Asian & $6(4)$ & $3(2)$ \\
\hline Others & $5(3)$ & $5(3)$ \\
\hline \multicolumn{3}{|c|}{ Socioeconomic status (ownership of house or car) } \\
\hline Not house or car & $12(8)$ & $12(8)$ \\
\hline Not house, $\geq 1 \mathrm{car}$ & $22(15)$ & $16(11)$ \\
\hline Own house, no car & $7(5)$ & $5(4)$ \\
\hline Own house, $\geq 1$ car & $102(71)$ & $110(76)$ \\
\hline \multicolumn{3}{|l|}{ Living arrangements } \\
\hline With family only & $121(84)$ & $123(85)$ \\
\hline With friends only & $18(13)$ & $16(11)$ \\
\hline $\begin{array}{l}\text { With partner and/or friends or } \\
\text { family }\end{array}$ & $4(3)$ & $4(3)$ \\
\hline Missing data & $1(1)$ & $1(1)$ \\
\hline \multicolumn{3}{|l|}{ Employment status } \\
\hline Employed & $36(25)$ & $38(26)$ \\
\hline School student & $52(36)$ & $51(35)$ \\
\hline University student & $50(35)$ & $46(32)$ \\
\hline Unemployed & $2(1)$ & $6(4)$ \\
\hline Home duties & $4(3)$ & $3(2)$ \\
\hline
\end{tabular}

were lost to follow-up, resulting in 144 cases from whom questionnaire data were collected.

Of the 144 controls, 55 (38\%) were the first control and 36 $(25 \%)$ were the second control approached. In $20 \%$ of cases, we recruited the fourth or greater control.

Of the 144 case-control pairs, 74 (51\%) were male (table 1). The median age at referral was 17.6 for cases and 17.7 for controls. Median time from admission of the case to interview was 53 (range 4-343) days for cases and 64 (19-317) days for controls.

Microbiological confirmation of diagnosis was available for 114 cases; positive on polymerase chain reaction in $50(44 \%)$, positive on culture in $38(33 \%)$, and positive on serology in 111 $(97 \%)$. Sixty six $(58 \%)$ strains were due to serogroup B, $43(38 \%)$ serogroup C, $1(0.9 \%)$ serogroup W135, 1 (0.9\%) serogroup Y, and 3 were ungroupable. We found no significant differences between microbiologically proved and unproved cases in terms of admission to intensive care or symptoms of illness.

In the univariate matched analysis of biological factors, case patients were significantly more likely to report being unwell with a preceding illness in the fortnight before admission than were the controls in the fortnight before interview $(\mathrm{P}=0.001$; table 2). Samples for viral serology were available for 105 case-control pairs (73\%). More cases than controls were positive for Epstein-Barr virus antiviral capsid antibody $\operatorname{IgG}(\mathrm{P}=0.12)$; three of $129(2 \%)$ cases and none of 116 controls were IgM positive. We found no differences between cases and controls in the proportions with influenza A H3N2 or H1N1 titres $>320$ or influenza B titres $>80$. Of 81 cases with paired serology, nine $(11 \%)$ showed at least a fourfold rise for influenza A (H3N2 7, H1N1 2), and five $(6 \%)$ showed at least a fourfold rise for influenza B. The trend was for preterm birth (defined as $<37$ weeks' gestation) to be associated with increased risk. Our a priori hypothesis didn't define 30 weeks as an important cut-off
Table 2 Univariate analyses for biological factors. Values are numbers (percentages) unless otherwise indicated

\begin{tabular}{|c|c|c|c|c|}
\hline Variable & Cases & $\begin{array}{l}\text { Controls } \\
(\mathrm{n}=144)\end{array}$ & $\begin{array}{l}\text { Matched odds } \\
\text { ratio }(95 \% \mathrm{Cl})\end{array}$ & $P$ value \\
\hline Preceding illness* & $\begin{array}{c}76 / 144 \\
(53)\end{array}$ & $45 / 144$ (31) & 2.3 (1.4 to 3.7 ) & 0.001 \\
\hline $\begin{array}{l}\text { Preceding illness (controlled } \\
\text { for "high" season of } \\
\text { meningococcal disease) }\end{array}$ & - & - & 2.0 (1.2 to 3.3$)$ & 0.006 \\
\hline $\begin{array}{l}\text { Epstein-Barr virus (positive } \\
\text { for viral capsid antibody } \\
\text { lgG) }\end{array}$ & $\begin{array}{c}105 / 129 \\
(81)\end{array}$ & $89 / 116$ (77) & 1.8 (0.9 to 3.6$)$ & 0.12 \\
\hline $\begin{array}{l}\text { Mannose-binding lectin (very } \\
\text { low producers) }\end{array}$ & $\begin{array}{c}20 / 112 \\
(18)\end{array}$ & $13 / 111$ & 1.3 (0.6 to 3.0$)$ & 0.53 \\
\hline $\begin{array}{l}\text { Influenza H3N2 convalescent } \\
\text { titre }>320\end{array}$ & $\begin{array}{c}48 / 116 \\
(41)\end{array}$ & $45 / 120$ & 1.2 (0.6 to 2.2$)$ & 0.63 \\
\hline $\begin{array}{l}\text { Influenza H1N1 convalescent } \\
\text { titre }>320\end{array}$ & $\begin{array}{c}16 / 116 \\
(14)\end{array}$ & $16 / 120$ & 0.8 (0.3 to 2.1) & 0.62 \\
\hline $\begin{array}{l}\text { Influenza B convalescent titre } \\
>80\end{array}$ & $10 / 116$ (9) & $8 / 120(7)$ & 1.2 (0.4 to 3.5) & 0.78 \\
\hline $\begin{array}{l}\text { Received meningococcal } \\
\text { vaccination (polysaccharide } \\
\text { or conjugate) }\end{array}$ & $\begin{array}{c}37 / 144 \\
(26)\end{array}$ & $54 / 143$ (38) & $0.4 \quad(0.2$ to 0.8$)$ & 0.01 \\
\hline $\begin{array}{l}\text { Born at less than } 37 \\
\text { completed weeks of } \\
\text { pregnancy }\end{array}$ & $\begin{array}{c}14 / 142 \\
(10)\end{array}$ & $7 / 140$ (5) & 2.2 (0.8 to 5.7) & 0.12 \\
\hline
\end{tabular}

(this was defined as 37 weeks). However, after data collection was complete and during further analysis of data, we found that five cases but no controls were born at gestation of 30 weeks or less.

Throat or pernasal swab specimens came from 86 cases and 139 controls. We found no positive results on polymerase chain reaction from throat or pernasal swabs for influenza A or B, mycoplasma or respiratory syncytial virus. Samples for mannose-binding lectin analysis were available for 92 pairs $(64 \%)$. Low production of mannose-binding lectin was not associated with disease. Immunisation was protective, and preterm delivery was linked with increased risk.

In the univariate analysis of health behaviours and social variables (table 3), factors associated with greater risk included having more than one intimate kissing contact and sharing a bedroom. Lower risk was associated with attending a religious ceremony at least once a week. Living in dormitory accommodation and socioeconomic status measured by subject's occupation or by using a composite variable of car and home ownership were not significant.

\section{Multivariate analysis}

In the final model, factors independently associated with higher risk of meningococcal disease were history of preceding illness, intimate kissing, being a student and preterm birth (table 4). Factors independently associated with lower risk included religious observance and having received a vaccine against serogroup $\mathrm{C}$ meningococci. Multivariate analysis using only microbiologically confirmed cases resulted in less power but gave similar results except for preterm birth (odds ratio $2.3,95 \%$ confidence interval 0.5 to $10.0, \mathrm{P}=0.3)$ and attendance at religious ceremonies $(0.13$, 0.01 to $1.4, \mathrm{P}=0.09$ ). Regular active smoking, passive smoking, use of illegal drugs, bedroom sharing, and socioeconomic status were not independently associated with risk. Use of the registrar general's classification for parental occupation as a measure of socioeconomic status instead of the composite variable of car or home ownership, did not materially change the final model.

\section{Discussion}

Risk factors for meningococcal disease in adolescents differ from those in childhood. We conducted a large population based 
Table 3 Univariate analyses for health behaviours and social variables. Values are numbers (percentages) unless otherwise indicated

\begin{tabular}{|c|c|c|c|c|}
\hline Exposures & $\begin{array}{l}\text { Cases } \\
(n=144)\end{array}$ & $\begin{array}{r}\text { Controls } \\
(\mathrm{n}=144)\end{array}$ & $\begin{array}{l}\text { Matched odds } \\
\text { ratio }(95 \% \mathrm{CI})\end{array}$ & $P$ value \\
\hline Regular smoker & $47(33)$ & $45(31)$ & 1.1 (0.6 to 1.8$)$ & 0.8 \\
\hline $\begin{array}{l}\text { Multiple close contacts who } \\
\text { smoke }^{*}\end{array}$ & $104(72)$ & $92(64)$ & 1.6 (0.9 to 2.7) & 0.11 \\
\hline $\begin{array}{l}\text { Regular consumption of illegal } \\
\text { drugs (once a week or more) }\end{array}$ & $23(16)$ & $13(9)$ & 2.3 (1.0 to 5.2 ) & 0.06 \\
\hline Any alcohol consumed ${ }^{\star}$ & $123(85)$ & $113(78)$ & 1.6 (0.9 to 3.0$)$ & 0.13 \\
\hline Regular partner & $60(42)$ & $54(38)$ & $1.2(0.7$ to 1.9$)$ & 0.45 \\
\hline $\begin{array}{l}\begin{array}{l}\text { Multiple intimate kissing } \\
\text { contacts }^{\star}\end{array} \\
\end{array}$ & $42(29)$ & $22(15)$ & 2.1 (1.2 to 3.7$)$ & 0.009 \\
\hline Shared bedroom* & $96(67)$ & $74(51)$ & 2.1 (1.2 to 3.6$)$ & 0.006 \\
\hline $\begin{array}{r}\text { Lives in dormitory } \\
\text { accommodation }\end{array}$ & $10(7)$ & $8(6)$ & 1.4 (0.4 to 4.4) & 0.6 \\
\hline Attended bar or party* & $128(89)$ & $115(80)$ & $2(1.0$ to 3.9$)$ & 0.04 \\
\hline Daily visit to friends home ${ }^{*}$ & $31(22)$ & $15(10)$ & 2.3 (1.2 to 4.6$)$ & 0.01 \\
\hline $\begin{array}{l}\text { Attended one or more religious } \\
\text { ceremonies* }\end{array}$ & $6(4)$ & $15(10)$ & 0.3 (0.1 to 0.9$)$ & 0.04 \\
\hline
\end{tabular}

Socioeconomic status

Categorical variable based on

home and car ownership (odds

ratio relative to owning neither

home nor car)†:

$\begin{array}{lllll}\text { No home and no car } & 12(8) & 12(8) & 1.0 & -\end{array}$

ownership

$\begin{array}{lllllll}\text { One or more cars but do not } & 22(15) & 16(11) & 1.4(0.5 \text { to 4.4) } & 0.5\end{array}$ own home

$\begin{array}{llllll}\text { Own home but no car } & 7(5) & 5(4) & 1.4(0.3 \text { to } 6.6) & 0.6\end{array}$

$\begin{array}{lllllll}\text { One or more cars plus own } & 102(71) & 110(76) & 0.9(0.4 \text { to 2.3) } & 0.8\end{array}$

home

Subject's occupational status

(odds ratio relative to being

employed):

\begin{tabular}{lccccc}
\hline Employed & $36(25)$ & $38(27)$ & 1.0 & - \\
\hline University student & $50(35)$ & $46(32)$ & $1.2(0.6$ to 2.4$)$ & 0.7 \\
\hline School student & $52(36)$ & $51(36)$ & $1.1(0.4$ to 2.8$)$ & 0.8 \\
\hline Others & $5(4)$ & $8(6)$ & $0.6(0.2$ to 2.5$)$ & 0.5
\end{tabular}

*In the fortnight period before illness (cases) or interview (controls).

†ln most cases, this refers to the parents-see methods for clarification.

study of risk factors for meningococcal disease in adolescents and a specific epidemiological investigation of disease risk during the adolescent peak (in 15-19 year olds).

\section{Role of preceding illness}

Independent biological risk factors for meningococcal disease included a history of preceding illness and preterm birth. A preceding illness has previously been identified as a risk factor, ${ }^{9} 12151632$ and we confirmed this by using a symptom based definition of preceding illness. Preceding illness occurred in 53\% of cases and $31 \%$ of controls so was neither necessary nor suffi-

Table 4 Multivariate analysis of risk factors for meningococcal disease

\begin{tabular}{lcc} 
Exposures & $\begin{array}{c}\text { Matched odds ratio } \mathbf{( 9 5 \%} \\
\text { CI) }\end{array}$ & P value \\
\hline Vaccinated against serogroup C meningococci & $0.12(0.04$ to 0.37$)$ & $<0.001$ \\
\hline Multiple intimate kissing contacts & $3.7(1.7$ to 8.1$)$ & 0.001 \\
\hline Attended one or more religious ceremonies ${ }^{*}$ & $0.10(0.02$ to 0.58$)$ & 0.01 \\
\hline $\begin{array}{l}\text { Preceding illness } \\
\text { Born at less than } 37 \text { completed weeks of } \\
\text { pregnancy }\end{array}$ & $2.9(1.4$ to 5.9$)$ & 0.003 \\
\hline \begin{tabular}{l} 
Occupational status (odds ratio relative to being employed) \\
\hline University student
\end{tabular} & $3.4(1.0$ to 13.5) & 0.05 \\
\hline School student & $3.3(0.8$ to 13.0) & 0.03 \\
\hline
\end{tabular}

Odds ratio adjusted for all other factors shown and controlled for parental car or home ownership and meningococcal disease season. Data for all variables available in 130 pairs. Excluding the gestation variable did not confound odds ratio estimates and model then included 136 pairs.

${ }^{*}$ In the fortnight period before illness (cases) or interview (controls). cient for disease. Its significance was unchanged after adjustment for high season of meningococcal disease or influenza. The precise aetiology of this preceding illness is unclear and may be a heterogeneous array of respiratory viruses. A case-control study of epidemic meningococcal disease in sub-Saharan Africa implicated adenovirus, parainfluenza, rhinovirus, mycoplasma, and respiratory syncytial virus. ${ }^{15}$ However, similar to Stuart et al,,$^{33}$ we found no evidence for respiratory syncytial virus being a predisposing agent. Our data did not support a role for Epstein-Barr virus or influenza infection, similar to findings from another recent study. ${ }^{12}$ However, outbreak ${ }^{143435}$ and surveillance data linkage studies ${ }^{36}$ show that influenza may predispose to meningococcal disease. It is likely that our cases were no longer shedding virus by the time of recruitment, but serological results were not supportive.

\section{Possible association with weeks of gestation}

The association of preterm birth and disease has not been described previously and should be interpreted with caution. Significance was lost when only microbiological confirmed cases were included. Our hypothesis was that gestation $<37$ weeks increased risk.

Interestingly, we found that five of our case patients but no controls were born at gestation of 30 weeks or less. This association may be a chance finding, biased by parental report, or, perhaps, could reflect real differences in immune function programming related to timing of birth. ${ }^{37}$ We did not find a significant relation between genetic determinants of production of mannose-binding lectin and risk of disease despite evidence that deficiency in mannose-binding lectin is a risk factor in young children. ${ }^{13}$ This may reflect lack of power, but it supports recent suggestions that mannose-binding lectin becomes less important in protecting against meningococcal disease with increasing age as elements of the acquired immune system mature. ${ }^{39}$

\section{Association with kissing}

Several adolescent health behaviours were significantly associated at univariate level, but only deep kissing with multiple partners remained independently significant in the multivariate model. This association has not been noted before in studies of college students and older adults. ${ }^{9}{ }^{12}$ Kissing on the mouth has been suggested to be a risk factor in children, ${ }^{11}$ but we found no evidence supporting this in adolescents (data not shown). Intimate kissing has been shown to be a risk factor for the carriage of meningococci in university students ${ }^{40}$ and it is likely that intimate kissing with multiple partners increases risk of transmission. Sharing a bed or bedroom and having a partner were not significant in the model if intimate kissing was included, which implies that risk derives from oropharyngeal exchange rather than other behaviours related to proximity. Any public health message for young people emphasising that deep kissing with multiple partners increases risk of acquiring serious infections may influence a small subset to change behaviour. Evidence from randomised trials shows that health promotion to young people through general practice can beneficially influence risk behaviours, ${ }^{41}$ although the impact is likely to be small.

Given that we have shown that preceding upper respiratory infection is an important risk factor for meningococcal disease, our work provides an evidential basis for the UK Department of Health campaign for a teenager to "look out for your mate" (http://www.immunisation.nhs.uk/files/loymleaflet.pdf, accessed 23 May 2005), as apparent flu-like illness or hangover may in fact be the early stages of meningococcal sepsis. 


\section{Other possible risk factors}

We found no significant role for active or passive smoking in adolescents, similar to previous findings in young adults, ${ }^{92}$ but in contrast to evidence that passive smoke exposure is a risk factor in children, ${ }^{11}{ }^{12}$ who are more likely to be exposed to meningococci because of higher carriage rates in smoking parents. ${ }^{43}$

Recent attendance at a religious event was linked to lower risk of meningococcal disease, as reported elsewhere. ${ }^{23}$ The odds ratio was minimally changed when only microbiologically confirmed cases were included. The association was confirmed when the analysis was repeated for habitual religious attendance in the previous year (data not shown), indicating minimal bias due to non-attendance by cases because of preceding or prodromal illness. Religious observance has been associated with lower risk for all cause mortality ${ }^{44}$ substance abuse, and sexual risk taking in adolescents ${ }^{45}$ and has beneficial immune effects. ${ }^{46}$ The most plausible explanation for our finding is that attendance at a religious event is associated with other lifestyle factors that promote health and protect against infection ${ }^{44}$ and that were not fully accounted for in our multivariate analysis.

University and school students were at higher risk of meningococcal disease than people in employment. Contrary to previous reports, ${ }^{910}$ we did not find that living in dormitory-style accommodation increased risk, although numbers were small ( $7 \%$ of cases, $6 \%$ of controls).

Student status may increase risk through crowding and increased social mixing, or through increased "risky" behaviours compared with employed young people of the same age.

\section{Limitations of our study}

Our findings are susceptible to the biases common to case-control studies ${ }^{47}$ despite efforts to minimize selection and recall biases and confounding. Recruitment of cases and controls was population based and prospective. Only $4.5 \%$ of eligible case patients refused participation. Although $63 \%$ of our recruited controls were either the first or second approached, 20\% were the fourth or greater approached. This is a source of selection bias, as these secondary controls may well be different from those not willing to participate (and this may relate to risk of exposure to meningococcal disease). Further, findings concerning religious observance may be confounded by control selection, in that highly observant young people may be more likely to volunteer. The approach taken of asking the case about a different time period to the control may introduce bias; however, the limitation of our approach has been addressed and at least partially validated in a recent statistical paper that used data from our study. ${ }^{48}$ It addressed the question: does disease incidence, and possibly other risk factors, vary with time of year, and concluded that the effect of risk factors and interactions may be adjusted for the time of year effect in a standard condition logistic regression analysis (as our paper has done) without introducing any bias.

We attempted to avoid recall bias by using a short recall period, memory aides, and a different recall period for cases and controls (adjusted for by a seasonal variable). The median times between hospital admission and interview for the case and control were 53 and 64 days, respectively, highly comparable to those in a recent case-control study of invasive pneumococcal disease by Nuorti et al. ${ }^{49}$ However, this study asked the case and control about the month before the case patient's illness, which was easier to do as their questions related more to habitual behaviour, which is easier to remember.

Excluding the few cases that died biased our sample towards less severe cases. Restricting analysis to microbiologically proved

\section{What is already known on this topic}

The incidence of meningococcal disease has two peaks: in early childhood and in adolescence

The incidence and case fatality rate in UK teenagers increased dramatically in the mid to late 1990s

Students living in dormitories are at greater risk than the general population of adolescents, but little is known of the risk factors for most cases of meningococcal disease in adolescents

\section{What this study adds}

Risk factors for meningococcal disease in adolescence differ from those in childhood

Independent risk factors include having multiple intimate kissing partners, history of preceding upper respiratory tract illness, preterm birth, and being a student

Reduced risk was associated with religious ceremony attendance and meningococcal vaccination

Changing personal behaviours could reduce the risk of meningococcal disease in adolescence

cases showed minimal confounding of the identified risk factors apart from preterm birth. A further potential source of bias arises from preceding or prodromal illness, as a reduction in risk behaviours in those who are becoming ill may underestimate the effect of risk factors for meningococcal disease and over-estimate protective effects. However, analysis of long term habitual data on active smoking and religious attendance indicated that behaviour change due to illness was not a significant source of bias.

\section{Conclusions}

We identified a pattern of risk and protection for meningococcal disease in adolescence different from that seen in younger children. Intimate kissing with multiple partners, preceding illness, and being a student conferred higher risk of disease, whereas religious attendance and receipt of a meningococcal vaccine were associated with lower risk. Factors that are important in meningococcal disease risk in younger children, such as passive smoking and deficiency of mannose-binding lectin, were not significant in adolescence. Our findings imply that changing personal behaviours could reduce the risk of meningococcal disease in adolescence. Although behaviour based health promotion messages might have a small role in reducing the risk of disease, such campaigns are unlikely to have a major impact. The development of further effective meningococcal vaccines therefore remains a key public health priority. ${ }^{50}$

Many thanks to all those who have contributed substantially to this work: Dorothy Crawford, Elizabeth Haworth, Robert George, Tim Harrison, Mary Ramsay, Mac Turner, Mike Levin, Diane Melvin, Steve Gray, Alan Blackwell, Julie Roberts, Jennie Borg, Jane Scotland, Helen Bedford, Stuart Logan, and Angie Wade and the many clinicians and public health doctors who referred cases.

Contributors: JT coordinated the study and drafted the manuscript. PGC was primarily responsible for data cleaning and analysis and contributed to manuscript revisions. JMS, MZ, CP, and EK contributed to study design, analysis, and manuscript revisions. $\mathrm{CB}$ and $\mathrm{NK}$ analysed genetic data and contributed to manuscript revisions. MZ was also responsible for laboratory 


\section{Research}

analysis of viral data. RMV and RB designed the study, analysed data, and revised the manuscript. RB is guarantor.

Funding: Meningitis Research Foundation, UK; in addition, the Wolfson Foundation provided an equipment grant. RMV is supported by the Health Foundation.

Competing interests: RB has acted as a paid consultant for Wyeth, GlaxoSmithKline, and Aventis Pasteur. MZ has received honoraria from Berna Biotech to speak at industry conferences on influenza. The UK Health Protection Agency has received funding from Chiron vaccines, Wyeth vaccines, Aventis Pasteur, Roche, and GlaxoSmithKline to carry out analytical work on a contractual basis in MZ's laboratory.

Ethical approval: North Thames multicentre research ethics committee and 125 local research ethics committees.

1 Jones DM, Mallard RH. Age incidence of meningococcal infection England and Wales, 1984-1991. J Infect 1993;27:83-8.

2 Ramsay M, Kaczmarski E, Rush M, Mallard R, Farrington P, White J. Changing patterns of case ascertainment and trends in meningococcal disease in England and Wales. Commun Dis Rep CDR Rev 1997;7:R49-R54

3 Harrison LH, Pass MA, Mendelsohn AB, Egri M, Rosenstein NE, Bustamante ARN, et al. Invasive meningococcal disease in adolescents and young adults. JAMA 001.286.694-9.

4 Connolly M, Noah N. Is group C meningococcal disease increasing in Europe? A report of surveillance of meningococcal infection in Europe 1993-6. European Meningitis Surveillance Group. Epidemiol Infect 1999;122:41-9

5 Davison KL, Crowcroft NS, Ramsay ME, Begg NT, Kaczmarski E, Stuart JM, et al. Enhanced surveillance system for suspected meningococcal disease in five regional health authorities in England:1998. Commun Dis Public Health 2002;5:205-12.

6 Bose A, Coen P, Tully J, Viner R, Booy R. Effectiveness of meningococcal C conjugate vaccine in teenagers in England. Lancet 2003;361:675-6.

7 Coen PG, Cartwright K, Stuart JM. Mathematical modelling of infection and disease due to Neisseria meningitides and Neisseria lactamica. Int J Epidemiol 2000;29:180-8.

8 Cartwright KAV, Stuart JM, Jones D, Noah ND. The Stonehouse survey: nasopharyngeal carriage of meningococci and Neisseria lactamica. Epidem Inf

9 Bruce MG, Rosenstein NE, Capparella JM, Shutt KA, Perkins BA, Collins M. Risk Factors for Meningococcal Disease in College Students. JAMA 2001;286:688-93.

10 Harrison LH, Dwyer DM, Maples CT, Billmann L. Risk of meningococcal infection in college students. JAMA 1999;281:1906-10.

11 Stanwell-Smith RE, Stuart JM, Hughes AO, Robinson P, Griffin MB, Cartwright K. Smoking, the environment and meningococcal disease: a case control study. Epidem Inf 1994;112:315-28.

12 Robinson P, Taylor K, Nolan T. Risk factors for meningococcal disease in Victoria, Australia in 1997. Epidem Inf 2001:127:261-8

13 Hibberd ML, Sumiya M, Summerfield JA, Booy R, Levin M. Association of variants of the gene for mannose-binding lectin with susceptibility to meningococcal disease. Lanet 1999:353:1049-53.

14 Cartwright K, Jones D, Smith AJ, Stuart JM, Kaczmarski EB, Palmer SR. Influenza A and meningococcal disease. Lancet 1991;338:554-7.

15 Moore PS, Hierholzer J, DeWitt W, Gouan K, Djore D, Lippeveld T, et al. Respiratory Viruses and Mycoplasma as Cofactors for Epidemic Group A Meningococcal Meningitis. JAMA 1990;264:1271-5.

16 Haneberg B, Tonjum T, Rodahl K, Gedde-Dahl TW. Factors preceding the onset of meningococcal disease, with special emphasis on passive smoking, stressful events, physical fitness and general symptoms of ill health. NIPH Annals 1983;6:169-73.

17 Moodley JR, Coetzee N, Hussey G. Risk factors for meningococcal disease in Cape Town. S Afr Med J 1999:89:57-9.

18 Imrey PB, Jackson LA, Ludwinski PH, England AC, III, Fella GA, Fox BC, et al. Outbreak of serogroup $\mathrm{C}$ meningococcal disease associated with campus bar patronage. Am J Epidemiol 1996;143:624-30.

19 Evans AS, Niederman JC. Epstein- Barr Virus. In: Evans AS, Kaslow RA, eds. Viral infections of humans: epidemiology and control. New York: Plenum Press, 1998:253-80.

20 Junker AK, Ochs HD, Clark EA, Puterman ML, Wedgwood RJ. Transient immune deficiency in patients with acute Epstein-Barr virus infection. Clin Immunol Immunopatho 1986;40:436-46.

21 Tashkin DR, Baldwin GC, Sarafian T, Dubinett S, Roth MD. Respiratory and immunologic consequences of marijuana smoking. J Clin Pharmacol 2002;42:71S-81S.

22 Kutscher S, Heise DJ, Banger M, Saller B, Michel MC, Gastpar M, et al. Concomitan endocrine and immune alterations during alcohol intoxication and acute withdrawal in alcohol-dependent subjects. Neuropsychobiology 2002;45:144-9.

23 Fischer M, Hedberg K, Cardosi P, Plikaytis B, Hoesly FC, Steingart KR, et al. Tobacco smoke as a risk factor for meningococcal disease. Pediatr Infect Dis J 1997;16:979-83.

24 Tully J, Ninis N, Booy R, Viner R. The new system of review by multicentre research ethics committees: prospective study. BMJ 2000;320:1179-82

25 Gray SJ, Borrow R, Kaczmarski E. Meningococcal serology. In: Pollard AJ, Maiden M, eds. Meningococcal disease: Methods and protocols. New Jersey: Humana, 2001:61-87.

26 Hotchin NA, Crawford DH. The diagnosis of Epstein Barr virus associated disease. In Morgan-Capner P, ed. Current topics in clinical virology. Cambridge: Cambridge University Press, 1991:115-40

27 Ellis JS, Fleming DM, Zambon MC. Multiplex reverse transcription-PCR for surveillance of influenza A and B viruses in England and Wales in 1995 and 1996. J Clin Microbiol 1997;35:2076-89.

28 Tong CY, Donnelly C, Harvey G, Sillis M. Multiplex polymerase chain reaction for the simultaneous detection of Mycoplasma pneumoniae, Chlamydia pneumoniae, and Chlamydia psittaci in respiratory samples.J Clin Pathol 1999;52:257-63.
29 Jack D, Bidwell J, Turner M, Wood N. Simultaneous genotyping for all three known structural mutations in the human mannose-binding lectin gene. Hum Muta 1997;9:41-6.

30 Turner MW, Dinan L, Heatley S, Jack DL, Boettcher B, Lester S, et al. Restricted polymorphism of the mannose-binding lectin gene of indigenous Australians. Hum Mol Genet 2000;9:1481-6.

31 Hosmer DW, Lemeshow S. Wiley series in probability and mathematical statistics. Chichester: Wiley, 1989.

32 Kriz P, Bobak M, Kriz B. Parental smoking, socioeconomic factors, and risk of invasive meningococcal disease in children: a population based case-control study. Arch Dis Child 2000;83:117-21.

33 Stuart JM, Cartwright K, Andrews NJ. Respiratory syncytial virus infection and meningococcal disease. Epidem Inf 1996;117:107-11.

34 Young LS, LaForce FM, Head JJ, Feeley JC, Bennett JV. A simultaneous outbreak of meningococcal and influenza infections. N Engl J Med 1972;287:5-9.

35 Harrison LH, Armstrong CW, Jenkins SR, Harmon MW, Ajello CW, Miller GB, et al. A cluster of meningococcal disease on a school bus following epidemic influenza. Arch Intern Med 1991;151:1005-9.

36 Watson JM, Nicholas S, James P. Meningococcal infection and influenza: do surveillance data support an association? Options for the control of influenza III. Amsterdam: Elsevier cience, 1996:82-4.

37 Fanger NA, Voigtlaender D, Liu C, Swink S, Wardwell K, Fisher J, et al. Characterization of expression, cytokine regulation, and effector function of the high affinity IgG receptor FC gamma RI (CD64) expressed on human blood dendritic cells. J Immunol 1997;158:3090-8.

38 McDade TW, Beck MA, Kuzawa C, Adair LS. Prenatal undernutrition, postnatal environments, and antibody response to vaccination in adolescence. Am J Clin Nutr 2001;74:543-8.

39 Hibberd ML, Sumiya M, Summerfield JA, Booy R, Levin M. Mannose binding lectin and meningococcal disease. Lancet 1999;354:336.

40 Neal K, Van-Tam J, Jeffrey N, Slack RCB, Madeley RJ, Ait-Tahar K, et al. Changing carriage rate of neisseria meningitides among university students during the first week of rm: cross sectional study. BMJ 2000;320:846-9.

41 Walker Z, Townsend J, Oakley L, Donovan C, Smith H, Hurst Z, et al. Health promotion for adolescents in primary care: randomised controlled trial. BMJ 2002;325:524.

42 Nelson SJ, Charlett A, Orr HJ, Barker M, Neal K, Taylor C, et al. Risk factors for meningococcal disease in university halls of residence. Epidem Inf 2001;126:211-7.

43 Stuart JM, Cartwright K, Robinson PM, Noah ND. Effect of smoking on meningococcal carriage. Lancet 1989; 2(8665):723-5

44 McCullough ME, Hoyt WT, Larson DB, Koenig HG, Thoresen C. Religious involvement and mortality: a meta-analytic review. Health Psychol 2000;19:211-22.

45 Zaleski EH, Schiaffino KM. Religiosity and sexual risk-taking behaviour during the transition to college. J Adolesc 2000;23:223-7.

46 Koenig HG, Cohen HJ, George LK, Hays JC, Larson DB, Blazer DG. Attendance at eligious services, interleukin- 6 , and other biological parameters of immune function in older adults. Int J Psychiatry Med 1997;27:233-50.

47 Schulz KF, Grimes DA. Case-control studies: research in reverse. Lancet 2002;359:431-4.

48 Stallard N, Tombs L. Including a time-of-year effect in the analysis of a matched casecontrol study. Stat Med 2004;23:3193-207.

49 Nuorti JP, Butler JC, Farley MM, Harrison LH, McGeer A, Kolczak MS, et al. Cigarette smoking and invasive pneumococcal disease. Active Bacterial Core Surveillance Team. N Engl J Med 2000;342:681-9.

50 Bose A, Coen P, Tully J, Viner R, Booy R. Effectiveness of meningococcal C conjugate vaccine in teenagers in England. Lancet 2003;361:675-6.

(Accepted 14 November 2005)

doi $10.1136 / \mathrm{bmj} .38725 .728472 . \mathrm{BE}$

Academic Centre for Child Health, Queen Mary's School of Medicine and Dentistry at Barts and the London, University of London, London E1 1BB Joanna Tully clinical research fellow

Pietro G Coen statistician

Robert Booy professor of academic child health

Department of Paediatrics, Royal Free and University College Medical School, University College, London WC1E 6BT

Russell M Viner consultant in adolescent medicine and endocrinology

Centre for Paediatric Epidemiology and Biostatistics, Institute of Child Health, London WC1N 3JH

Catherine Peckham professor of paediatric epidemiology

Health Protection Agency (South West), Stonehouse GL10 3RF

James M Stuart consultant epidemiologist

Health Protection Agency, Respiratory Virus Unit, Health Protection Agency, London NW9 5HT

Maria Zambon head of respiratory virus unit

Infectious Diseases and Microbiology Unit, Institute of Child Health

Clare Booth research assistant

Nigel Klein professor of infectious diseases and immunology

Health Protection Agency, Meningococcal Reference Unit, Manchester Royal Infirmary, Manchester M13 9WZ

Ed Kaczmarski director

Correspondence to: R Booy robertb2@chw.edu.au 